\title{
Making a case for behaviour based learning strategies in supporting students' academic performance
}

\author{
Maeve Gallagher \\ Trinity College Dublin, Ireland \\ Dr Niamh Flynn \\ Dublin Business School, Ireland
}

\begin{abstract}
The aim of this article is to raise the profile of time and resource management interventions, not just as part of the delivery of Student Learning Development Services but as a core strategy, supported with interventions and resources that can be systematically evaluated, to help students (both undergraduate and postgraduate) maximise academic and employment potential.
\end{abstract}

This opinion piece puts forward a case for Student Learning Development practitioners to design and deliver interventions aimed at improving students' self-regulated learning skills. The case is illustrated by examples from research on self-regulated learning (e.g. Pintrich, 2004) and from reports on graduate employment figures (e.g. OECD - Heckmann, 2013) and employers' perceptions of graduates' employability skills (e.g. Council for Industry and Higher Education - Archer and Davison, 2008). There are also examples of interventions delivered by the Student Learning Development Service, Trinity College Dublin Ireland to help students improve self-efficacy and time management skills. The aim of this opinion piece is to stimulate discussion and ideas as to how educationalists and, in particular, professionals working in Student Learning Development Services in third level environments, can help students to develop these behavioural skills to enhance both their academic and employment potential.

Keywords: self-regulated learning; behavioural strategies; time-management; selfmanagement; employability; academic achievement; Student Learning Development Services. 


\section{Introduction}

The number of individuals across the European Union who are entering third level or tertiary education has increased in recent years. A summary from the OECD (Heckmann, 2013) on trends in education across the European Union reported that many countries can expect a significant increase in the number of their population that attain a tertiary education. In fact the report (based on results from $21 \mathrm{EU}$ countries) noted that a number of countries, including Ireland and the United Kingdom, have already met or exceeded the benchmark set (in the Target for Europe 2020 Strategy (Europe 2020 Targets, 2013)) to have at least $40 \%$ of 30-34 year olds completing third level education. The report identified that there is a strong relationship between high levels of education, employability and earning potential. Adults (25-64 age range) with a tertiary education earned $58 \%$ more in 2011 than adults in the same age group with second level education.

In a paper examining how universities can enhance graduate employability to meet the needs of a flexible and rapidly changing knowledge intensive economy, Bridgstock (2009) recommends a review of how terms such as employability and generic skills are understood and defined. A report on graduate employability produced by the Council for Industry and Higher Education UK (Archer and Davison, 2008) found that employers were not satisfied with the level of generic skills that graduates brought to the workplace. The report was based on the results of a pilot survey of 233 companies (including large, medium and small organisations) conducted by the Confederation of British Industry (2006). The research found that $30 \%$ of employers had problems with graduate skills, including team-working, communication, and problem solving, and 33\% were dissatisfied with graduate self-management skills. Although the sample size is quite small, the results have implications for employers, students and universities. Indeed, authors of the report (Archer and Davison, 2008) recommend that there is a need for action by stakeholders to address the real or perceived skills deficit in graduates.

In contrast, Bridgstock (2009) states that narrow definitions of employability have often been adopted by employers' organisations and also by joint university and business publications which focus on generic and discipline specific skills and initial employment outcomes. She notes that there is a tendency, in particular in the UK and Australia, to define graduate employability based on First Destination employment statistics, which measure success primarily based on graduates' abilities to secure and retain full time and 
permanent employment. The author recommends a model of employability in which higher education providers play a more active role in helping students to acquire and develop the lifelong learning and self-management skills to respond proactively and adapt to the needs of a rapidly changing knowledge based economy which has less of a focus on job security and long-term employment than in previous decades.

The next section will look at the research on self-regulated learning, and how this model and framework can be utilised by providers of learning services in third level environments to help students to become actively engaged in their own learning processes and outcomes.

\section{Self-regulated learning}

Self-regulated learning is a complex construct that is positioned at the junction of many different research traditions (Boekaerts, 1999) but, at a fundamental level, it can be understood as the process of systematically activating and sustaining cognitions, behaviours and emotions in order to achieve learning goals (Pintrich, 2004). Evidence has shown that academically successful students are self-regulated learners (e.g. McMillan, 2010) and that self-regulated learners and high achievers engage in time management activities (e.g. Zimmerman and Martinez-Pons, 1986). Pintrich (2004) identified four assumptions underpinning most models of self-regulated learning; 1 ) that the process is dynamic; 2) the process involves goal setting and active engagement on the part of the learner; 3 ) the learner can monitor, control and regulate some aspects of behaviour, cognition and motivation and the external environment; 4) self-regulation activities can mediate between personal and context specific attributes to impact on actual performance and achievement. Therefore, it seems that the use of self-regulation strategies may help learners to override personal or situational factors to enhance performance and academic outcomes, which is very encouraging for both students and educationalists and learning practitioners alike.

\section{Skill, will and self-management aspects of self-regulated learning}

In her study investigating how academically successful students learn, McMillan (2010) summarises the main aspects underpinning Pintrich's (2000; 2004) model of self-regulated 
learning, namely 'skills' (e.g. cognitive strategies, such as learning, memorising and understanding, and metacognitive strategies such as planning, monitoring and adjusting cognitive strategies in line with their appraised effectiveness) and 'will' (e.g. factors that influence motivation such as goal setting). In addition to cognitive, metacognitive and motivational factors, self-regulated learning involves behaviour or self-management strategies including time-management, support-seeking and managing the study environment (Pintrich, 2004).

Research on students' approaches to studying (e.g. task-orientated, performance oriented, socially orientated or avoiders) found that systematic and consistent management of time and planning of studies has been associated with rapid progress (Mäkinen and Olkinuoro, 2004). The researchers concluded that the ability to plan and regulate study may become a generalised skill that is used on an on-going basis rather than just as a coping strategy for a specific stressful situation. This suggests that planning and regulating study could be a strategy that students can develop over time which may become a habitual strategy for managing stress and improving academic achievement. Pintrich (2004) notes that students in postsecondary settings have more autonomy in terms of structuring their study environment to enhance learning, which is important as much of the learning takes place outside of the college setting. Monitoring and removing distractions, as well as having an environment which is conducive to studying, are important means of applying selfregulation strategies to facilitate learning (Zimmerman, 1998).

The next section will look in more detail at the relationship between behavioural selfregulated learning and achievement, with a particular focus on a research study by Flynn, Kinsella and O'Connor (2012).

\section{Exploring the relationship between behavioural self-regulated learning and academic achievement}

A cross-sectional study ( $n=598)$ on self-regulated learning and academic achievement in third level students (Flynn et al., 2012) found that behavioural self-regulation strategies, rather than cognitive self-regulation strategies, were a stronger predictor of academic achievement in high performing students. In addition, the findings in relation to stress showed that behavioural self-regulation was also a predictor of self-reported stress among 
students, with students higher in behavioural self-regulated learning reporting lower stress levels.

Flynn et al.'s (2012) research suggests behavioural strategies (such as managing time, study environment and seeking support) may be more general in nature (e.g. used by students in a consistent way regardless of course or study discipline) than cognitive strategies, (which may be more specific to context, course or individual differences). Therefore, interventions focusing on behavioural change in terms of management of time, effort and environment and help seeking may be beneficial to all students in terms of enhancing academic achievement.

Flynn et al. (2012) reported that behavioural self-regulation strategies most strongly correlated with academic achievement, indexed in terms of self-reported current grade, were management of time and study environment. Self-regulated learning strategies were measured using the Motivated Strategies for Learning Questionnaire (MSLQ; Pintrich et al., 1991). The study also found that certain groups within the sample reported a higher use of cognitive and behavioural strategies, namely mature students (over the age of 23 on entry to college) relative to non-mature students, and postgraduate students relative to undergraduate students.

Although the findings must be interpreted in the light of limited sample representativeness (that is the majority of participants reported grades of 2.1 and above), they suggest that interventions involving the direct teaching of skills including management of time and study environment and effort regulation should begin as early as possible at undergraduate level to ease the transition and adjustment into the third level environment, and to help bridge the gap between students' actual and expected academic performance.

\section{Self-regulated learning; from theory to practice}

According to Boekaerts (1999), the concept of self-regulated learning has been embraced by policy makers, teachers, educators and parents as key to successful learning in school and beyond. In her article Boekaerts notes that policy makers have devoted attention and funding to reorganising schools to incorporate powerful new learning environments that provide students with new opportunities to learn according to basic principles of self- 
regulated learning. However, she identifies the need to make a clear distinction between learning activities that are student-initiated versus learning activities that are teacher led. Boekaerts (1999) defines self-directed learning activities as spontaneous and driven by personal goals, whereas teacher initiated goals are driven by the wishes, needs and expectations of others. The researcher (Boekaerts, 1997) notes that in general, teachers tend to guide the learning process towards a specific learning outcome and she recommends that in order for self-regulated learning to develop, teachers must create powerful learning environments (in both formal settings and within every day learning) that enable the student to actively participate and reflect on the learning process. The author differentiates between 'external regulation', which leaves the learner with little responsibility for the learning process, and an alternative approach called 'scaffolding', in which the teacher provides an adaptable and temporary support system (to allow the student to develop expertise), eventually reverting to the role of coach, and finally receding support as the student gains confidence and experience (Boekaerts, 1997). Boekaerts also advocates that in order to become self-regulated learners, students should be allowed autonomy in choice of task, time management and learning strategies, with the opportunity to reflect on strategies used and effort allocation.

In summary, the literature on self-regulated learning supports the view that students can actively and proactively manage and develop their own cognitive, motivational and selfmanagement behaviours to enhance academic performance. Although evidence in the literature and in practice (e.g. learning development provision ) endorses interventions aimed at enhancing students' management of resources, time and study environment, it has been reported (Vrugt and Oort, 2008) that there is very little data available regarding the relationship between achieving goals and resource management strategies.

Undoubtedly, systematic evaluations of interventions are needed to clarify, firstly, whether interventions can lead to changes in behavioural self-regulation at third level, and secondly, whether changes in behavioural self-regulation are predictive of increase in academic performance. Pintrich (2004) states that the main goal of self-regulated learning models should be used to build conceptual, scientific models which can be tested empirically both in the laboratory and in the classroom, and through practical applications to help guide and inspire research in the field of student motivation and learning. 


\section{Behavioural self-regulated learning and Student Learning Development Services}

Boekaerts (1997) recommends that self-regulated learning should be 1) student rather than teacher led in terms of choice of task, learning strategy and management of time and 2) include opportunities for informal everyday learning, as well as learning in a formal environment. Therefore, this paper puts forward the opinion that Student Learning Development Services in Higher Education Institutes are in a key position to provide students with the scaffolding to become self-regulated learners who can manage their own time and resources to improve employability skills and academic performance. Providing students with support in terms of time management, self-management and resource allocation is already a core part of the services offered by many Student Learning Development Services. However, this article suggests that more concentrated interventions focused on helping students to develop the tools to regulate behaviour, will not only help improve academic performance, but will also help students to develop the employability skills required to adapt to an ever changing and challenging employment market. Also, Student Learning Development Services can provide an informal learning environment where the student decides on the personal or academic goals and behaviours they wish to focus on (as recommended by Boekaerts, 1999), whereas academic departments are focused on students achieving specific academic tasks and learning outcomes. In addition, Student Learning Development Services are concerned with both the academic and personal development of students, whereas other Student Support Services may have a more specific brief, e.g. the Student Counselling Service is concerned primarily with the personal and emotional development of the student and the Careers Advisory Service is concerned with helping students to develop and utilise employability skills to gain employment. Also, Student Learning Development Services activities include engagement of the student in the learning process, including goal setting, planning, time management and reflection on outcomes, which are core principles within self-regulated learning models (e.g. Pintrich, 2004). Therefore, Student Learning Development Services are in a strong position to provide students with the opportunities to develop behavioural self-regulation skills with the aim of enhancing academic performance and employability skills. The next section will look at specific examples of interventions from Trinity College Dublin Learning Development Services which were designed and implemented to help students improve time and resource management and academic performance. 


\section{Practical examples of interventions from Student Learning Development Services, Trinity College Dublin, to help students to develop time, study and resource management skills}

Student Learning Development Services in Trinity College Dublin, Ireland, provide individual, group and online support to help students to become active, proactive and selfregulated learners. The service provides individual consultations and a drop in service, as well as delivering generic skills workshops and customised workshops, to groups of students and departments. Student Learning Development Services are based on the principles of self-regulated learning theory, namely to help students to develop and utilise 'skill' 'will' and 'self-management' strategies to maximise academic achievement. Examples include interventions aimed at helping students to set, monitor and review learning goals, to develop critical thinking and problem solving skills, writing skills, and time and self-management skills. A core aim of the service is to help students to gain practical experience and knowledge of their behaviour and how it impacts on academic performance.

These types of interventions may be familiar to other providers of Student Learning Development Services within different universities. However, these examples illustrate how Student Learning Development Services can provide the scaffolding, learning opportunities, and practical experience to help students direct, reflect on and amend their own behaviours to enhance academic outcomes. The examples given here focus on helping students 1) to improve time management within an exam setting 2) address procrastination behaviour, and 3) enhance employability by gaining experience of training other students (e.g. through the Peer Mentorship Programme).

\section{Exam simulation}

An example of an intervention aimed at helping students to monitor, review and improve time and self-management skills is an exam simulation, where students can practise answering questions or writing notes under timed ( 2 hours) and simulated (exam hall) conditions prior to sitting the actual exam, as a way of practicing and improving time and study management strategies prior to the actual exam. The feedback from this event shows that students find it very helpful in terms of ironing out any poor study habits, such as poor use of time and study environment, and students develop a clear idea of their academic performance under realistic exam conditions. 


\section{Addressing procrastination and time management issues (pilot project)}

Another project aimed at helping students to address issues relating to time management and procrastination was a project piloted in 2012 and 2013, aimed at helping students to gain a better understanding of the reasons why they procrastinate and to help them to implement strategies to overcome this behaviour. Research on behavioural interventions for university students (Tuckman and Schouwenburg, 2004) found that behavioural interventions, such as restructuring the study environment, social or group influence, and task and time management resources, such as weekly schedules, can reduce, if not eliminate, procrastination behaviours.

The series of sessions run by the Student Learning Development Service at Trinity College Dublin were designed and delivered by Dr Tamara O'Connor (2013), Educational Psychologist and Student Learning Advisor. The workshops consisted of information provision, exercises, assessment, discussion, case studies, and homework, in particular looking at how the act of procrastinating impacted on participants' feelings and behaviours. Qualitative feedback from those who attended the sessions indicated that students found the intervention both helpful and reassuring in tackling and addressing procrastination issues. These anecdotal findings seem to suggest that behavioural self-regulation is responsive to intervention at third-level, however, in order to implement these interventions on a more formal and on-going basis, Student Learning Development Services would need to look at more systematic methods of evaluating the interventions, in addition to qualitative feedback and comments from students.

\section{'Train the trainer' sessions for student peer mentors}

Student Learning Development services in Trinity College Dublin work closely with academic departments and student groups concerned with enhancing the student experience and easing the transition into the third level environment. These include the undergraduate and postgraduate Students' Union bodies, the Mature Students Officer, and the Peer Mentor and Peer Support programme - (an initiative where students help fellow students with the challenges of the third level environment through social, personal and academic interventions). Student Learning Development Services provides 'train the 'trainer' sessions to peer mentors on a range of topics such as time and self-management and exam preparation, which the peer mentors then deliver via workshops to groups of fellow students. This activity helps the student mentors to gain experience in teaching and 
presenting to student groups, as well as helping to disseminate Student Learning Development interventions to a wider group of students.

Seeking support has been identified as an important aspect of self-regulated learning models (e.g. Pintrich, 2004) and a strong predictor of academic achievement (e.g. Flynn et al., 2012). By training student mentors to review and improve their own time-management and exam preparation skills, as well as supporting other students who need to improve these skills, Student Learning Development Services are encouraging students to develop self-regulated learning behaviours to enhance academic achievement and employability.

In summary, a key feature of Student Learning Development Services, Trinity College Dublin, is to provide students with practical opportunities to experience, evaluate and enhance their time and self-management skills (e.g. the Exam Simulation event and procrastination support group). Although the procrastination support group was conducted as a pilot study, a potential next stage in development would be to collaborate with students, and if possible, Learning Development Services in other universities to design, deliver and systematically evaluate interventions aimed at helping students to develop the time and self-management skills to enhance academic performance and employability skills.

\section{Conclusion}

The case for helping students to develop behavioural self-management skills is compelling both from an industry and academic perspective. The 'Education at a Glance report' (Heckmann, 2013) produced by the OECD shows an increase in the number of individuals across the European Union participating in third level education. The report also demonstrates that individuals with third level education have higher earning potential than their peers who do not have the same level of educational attainment.

There are a number of examples from research that advocate interventions to help students to improve the use of behavioural self-regulation strategies, such as time management, restructuring the study environment in order to enhance academic achievement (e.g. Tuckman et al., 2004; McMillan, 2010; Flynn et al., 2012). However, researchers (e.g. Vrugt and Oort, 2008) observe that there is a lack of data on the 
relationship between resource management and achieving goals, and Pintrich (2004) recommends the need for systematic evaluation of interventions.

In conclusion, research suggests that there is a lack of evidence on the relationship between the development of resource management behaviour and improved performance in students. This author recommends that Student Learning Development practitioners work collaboratively to design, deliver and evaluate interventions to build up a body of evidence and support for behavioural interventions aimed at enhancing students' selfregulated learning behaviour.

\section{References}

Archer, W. and Davison, J. (2008) Graduate employability: what do employers think and want? London: The Council for Industry and Higher Education [Online]. Available at: http://ec.europa.eu/education/higher-education/doc/business/graduate en.pdf (Accessed: 30 July 2013).

Boekaerts, M. (1997) 'Self-regulated learning: a new concept embraced by researchers, policy makers, educators, teachers and students', Learning and Instruction, 7(2), pp. 161-186.

Boekaerts, M. (1999) 'Self-regulated learning: where are we today?', International Journal of Educational Research, 31(6), pp. 445-457.

Bridgstock, R. (2009) 'The graduate attributes we've overlooked: enhancing employability through career management skills', Higher Education Research and Development, 28(1), pp. 31-44.

Confederation of British Industry (2006) CBI/Pertemps employment trends survey 2006. London: CBI Publications.

Europe 2020 Targets (2013) The 5 targets for the EU in 2020 [Online]. Available at: http://ec.europa.eu/europe2020/targets/eu-targets/index en.htm (Accessed: 1 August 2013). 
Flynn, N., Kinsella, W. and O'Connor, T. (2012) Self-regulated learning as a predictor of academic achievement and stress in third-level students. Unpublished Dissertation. University College Dublin.

Heckmann, C. (2013) 'European Union - country note', Education at a glance 2013: OECD Indicators [Online]. Available at: http://www.oecd.org/edu/ (Accessed: 1 August 2013).

Mäkinen, J. and Olkinuora, E. (2004) 'University students' situational reaction tendencies: reflections on general study orientations, learning strategies and study success', Scandinavian Journal of Educational Research, 48(5), pp. 477-491.

McMillan, W.J. (2010) "Your thrust is to understand' - how academically successful students learn', Teaching in Higher Education, 15(1), pp. 1-13.

O'Connor, T. (2013) Procrastination group report. Evaluation report. Student Learning Development Services Trinity College Dublin.

Pintrich, P.R., Smith, D., Garcia, T., and McKeachie, W. (1991) A manual for the use of the Motivated Strategies for Learning Questionnaire (MSLQ). Ann Arbour, MI: The University of Michigan.

Pintrich, P.R. (2000) 'The role of goal orientation in self-regulated learning', in Boekaerts, M., Pintrich, P.R. and Zeidner, M. (eds.) Handbook of self-regulation. San Diego, CA: Academic Press, pp. 451-502.

Pintrich, P.R. (2004) 'A conceptual framework for assessing motivation and self-regulated learning in college students', Educational Psychology Review, 16(4), pp. 385-407.

Tuckman, B.W. and Schouwenberg, H.C. (2004) 'Behavioural interventions for reducing procrastination among university students', in Schouwenburg, H.C., Lay, C.H., Pychyl, T.A. and Ferrari, J.R. (eds.) Counselling the procrastinator in academic settings. Washington DC: American Psychological Association, pp. 91-103. 
Vrugt, A. and Oort, F.J. (2008) 'Metacognition, achievement goals, study strategies and academic achievement: pathways to achievement', Metacognition and Learning, 3(2), pp. 123-146.

Zimmerman, B.J. and Martinez-Pons, M. (1986) 'Development of a structured interview for assessing student use of self-regulated learning strategies', American Educational Research Journal, 23(4), pp. 614-628.

Zimmerman, B.J. (1998) 'Academic studying and the development of personal skill: a selfregulatory perspective', Educational Psychology, 33(2/3), pp. 73-86.

\section{Author details}

Maeve Gallagher is a Student Learning Advisor with the Student Learning Development Services at Trinity College Dublin. Maeve is a chartered occupational psychologist (British Psychological Society). She has previously worked as a careers advisor (Dublin City University) and as a researcher in the area of continuous improvement and innovation (Centre for Research in Innovation Management, University of Brighton).

Dr Niamh Flynn is an Educational Psychologist and Lecturer of Psychology in Dublin Business School. Her research interests lie in self-regulated learning, procrastination and stress in third-level students. 